\title{
African leafy vegetables consumed by households in the Limpopo and KwaZulu-Natal provinces in South Africa
}

\begin{abstract}
${ }^{a}$ Faber M, PhD ${ }^{b}$ Oelofse A, PhD a Van Jaarsveld PJ, PhD c 'Wenhold FAM, PhD d Jansen van Rensburg WS, MSc a Nutritional Intervention Research Unit, Medical Research Council, South Africa ${ }^{\mathrm{b}}$ Centre for Nutrition, University of Pretoria, South Africa ${ }^{\mathrm{c}}$ Division of Human Nutrition, Faculty of Health Sciences, University of Pretoria, South Africa ${ }^{\mathrm{A}}$ Agricultural Research Council, Roodeplaat Vegetable and Ornamental Plant Institute, South Africa Correspondence to: Dr Mieke Faber, e-mail: mieke.faber@mrc.ac.za Keywords: African leafy vegetables; rural; urban; $\beta$-carotene; South Africa
\end{abstract}

\section{Abstract}

Objectives: The objectives of this study were to determine the availability of, access to and nutrition-related uses of African leafy vegetables in rural and urban households; and to determine the $\beta$-carotene content of the dominant African leafy vegetable.

Design: The study consisted of a qualitative explorative phase (field walks, semi-structured interviews with key informants, focus group discussions) at two rural sites; and a quantitative household survey (questionnaire) at two rural and one urban site. Amaranth leaves were analysed for $\beta$-carotene content.

Setting and subjects: The household survey included households at a rural site in Limpopo province $(n=100)$; and a rural $(n=101)$ and urban ( $n=391$ ) site in KwaZulu-Natal province, South Africa.

Results: A variety of edible plants were identified during field walks at the two rural sites. Focus group discussions narrowed this down to ten plants at the rural Limpopo site and six at the rural KwaZulu-Natal site. The most popular leaves were amaranth (Amaranthus spp), spider plant (Cleome gynandra), wild watermelon (Citrullus lanatus) and blackjack (Bidens spinosa), consumed individually or mixed with other leaves. Rural households procured leaves mostly from the wild whereas urban households relied more on informal markets. In Limpopo, leaves were dried and stored for consumption during winter. KwaZulu-Natal households considered African leafy vegetables food for the poor. Leaves were boiled in salted water, or steamed and then fried in oil. Fried and boiled amaranth leaves contained 627 and $429 \mu \mathrm{g}$ retinol activity equivalents/100 g respectively.

Conclusions: Availability of, access to and nutrition-related uses of African leafy vegetables are context-specific, with inter- and intraprovincial rural/urban differences. Information collected during small studies within a specific area can therefore not be generalised for the overall SouthAfrican population. Amaranth can potentially contribute significantly to vitamin A requirements of nutritionally vulnerable communities.

S Afr J Clin Nutr 2010;23(1):30-38

\section{Background}

A low intake of vegetables and fruit is among the top ten risk factors contributing to mortality worldwide. ${ }^{1}$ The World Health Organization (WHO) recommends a daily intake of more than $400 \mathrm{~g}$ of vegetables and fruit per person to protect against dietrelated chronic diseases. ${ }^{2}$ This is about double the amount consumed by the average South African. ${ }^{3}$ An increased intake of vegetables and fruit is therefore needed. However, rural and urban South African women in the KwaZulu-Natal (KZN) and Western Cape provinces consider affordability, and to a lesser extent availability, to be major constraints in the consumption of vegetables and fruit. ${ }^{4}$ Smith and Eyzaguirre ${ }^{5}$ argue that in sub-Saharan countries African leafy vegetables could play an important role in the WHO global initiative on increased consumption of vegetables and fruit.

In developing countries, the diets of the poor are predominantly cereal based and nutrient poor, with very little foods of animal origin, vegetables and fruit. A low intake of vegetables and fruit, particularly those rich in provitamin A carotenoids, contributes towards the high prevalence of vitamin A deficiency. For children younger than five years worldwide, an estimated 190 million are vitamin $A$ deficient ${ }^{6}$ and, in 2004, an estimated 0.6 million died because of vitamin $A$ deficiency. ${ }^{7}$ In South Africa, $64 \%$ of one- to nine-year-old children were shown to be vitamin A deficient in $2005 .^{8}$

Micronutrient supplementation and food fortification are shortand medium-term strategies to address the "hidden hunger" (i.e. micronutrient malnutrition), but in the long term dietary diversification through a food-based approach involving agriculture has been proposed as one of the more sustainable options..$^{9,10}$ Dietary diversification has to widen its scope to include indigenous crops, such as wild-growing green leafy vegetables. Although concerns with respect to the bioavailability of vitamin A from green leafy vegetables have been raised, ${ }^{11,12}$ consumption of cooked and pureed green leafy vegetables was shown to have a beneficial effect on improving vitamin A status. ${ }^{13-15}$ It stands to reason that wild green leafy vegetables could have a similar beneficial effect, particularly in rural resource-poor settings, and this possibility has repeatedly been raised. ${ }^{16,17}$ The potential value for food security and rural development 
of gathering wild foods, growing locally adapted varieties and eating from the local ecosystem, is recognised by an international initiative (under the umbrella of the Convention of Biological Diversity) lead by the Food and Agriculture Organization of the United Nations (FAO), together with Bioversity International (formerly IPGRI, International Plant Genetic Resources Institute), with the overall aim to promote the sustainable use of biodiversity in programmes contributing to food security and human nutrition. ${ }^{18}$

In South Africa, morogo and imifino are traditional terms used for a collection of various dark-green leaves that are eaten as a vegetable; the leaves either grow wild or come from vegetables such as pumpkin, beetroot and sweet potato. In this paper the term 'African leafy vegetables' will be used to refer to the collective of leafy vegetables that usually grow wild. People in rural areas have free access to these green leafy vegetables, where they can harvest them from either the wild, fallow land or home gardens. Urban people do not have these opportunities, as they have limited access to fallow land and wild spaces, and often less space is available for home gardens.

The potential effect of African leafy vegetables on the nutritional status of a particular population will depend, among other things, on the species that are geographically and seasonally available; the species that are known and socio-culturally acceptable or popular as food; and the frequency of consumption and the amount consumed. The aim of this study was to determine the availability of, access to and nutrition-related uses of African leafy vegetables in two rural and one urban site in South Africa, and to analyse a prominent African leafy vegetable for $\beta$-carotene content.

\section{Methods}

\section{Study population}

The study was done after the first summer rains, during 0ctober, November and December 2008. The first phase of the study was explorative and entailed collecting quantitative data at a rural site in both the Limpopo and KZN provinces in South Africa. This was followed by a quantitative household survey. In addition to the two rural sites, the quantitative household survey was also done at an urban site in the KZN province.

In the Limpopo province (where the term morogo is used), the rural villages selected for this study were located in the Greater Sekhukhune district municipality and within the local municipality of Makhudutamaga. Greater Sekhukhune forms part of one of the Integrated Sustainable Rural Development (ISRD) nodes. ISRD nodes consist of districts and local municipalities that have been prioritised by the South African government for development as they are some of the poorest areas in the country, and are characterised by poor infrastructure, limited resources and economic depression. The study site is a plateau area that is relatively eroded, with generally shallow soils and limited vegetation cover.

In the KZN province (where the term imifino is used), data were collected at both a rural and an urban site. The rural site, a mountainous village falling under the KwaXimba tribal authority bordering The Valley of a Thousand Hills just north of Pinetown, has a rugged terrain, is relatively inaccessible, and has steep slopes with mainly shallow soils that limit cultivation. A home-garden project promoting the cultivation of dark-green leafy vegetables, among others, was conducted in the area from 1998 to $2002 .{ }^{19}$ The urban site, which has a low socio-economic level, is situated in the Mariannhill area, Pinetown, approximately $20 \mathrm{~km}$ south of the rural site, and is more densely populated.

The study included a qualitative explorative phase consisting of observations and semi-structured interviews with key informants as well as focus group discussions to determine the availability and use of African leafy vegetables at the two rural sites. This was followed by a quantitative household survey to determine procurement and consumption of morogo/imifino at the three study sites. Finally, analysis of the $\beta$-carotene content of three forms of the dominant African leafy vegetable was performed. The study was approved by the Ethics Committee: Faculty of Natural and Agricultural Sciences of the University of Pretoria (EC080826-036). Respondents who were interviewed gave written consent after the purpose and nature of the study were explained to them.

\section{Observations and key informant interviews at the rural sites}

Following a site visit, support and permission for the study were obtained from the local tribal authorities. A spokesperson at each rural site was asked to identify key informants who were considered the most knowledgeable people regarding the traditional uses of African leafy vegetables. These key informants assisted during field walks to identify African leafy vegetables available in the village. Photographs were taken of the plants in their natural habitat and the local name of the plant was recorded. A sample of each plant was collected for identification of the scientific and popular English name by a horticulturist from the Agricultural Research Council's Vegetable and Ornamental Plant Institute with assistance from the South African National Biodiversity Institute.

Semi-structured interviews were conducted with the key informants on the availability of and access to the African leafy vegetables, beneficial traits, constraints related to the consumption and production (where applicable), their household use, and beliefs and practices at the two rural study sites. The key informants comprised six females, aged between 38 and 49 years, at the rural Limpopo site, and eight females, aged between 38 and 60 years, at the rural KZN site.

\section{Focus group discussions at the rural sites}

The key informants recruited participants for the focus group discussions. In total, eight focus group discussion meetings were held; two with younger women (18 to 30 years) and two with older women (45 years and older) at each of the two rural sites. Purposive sampling was used to select between eight and twelve women who were considered knowledgeable regarding African leafy vegetables per focus group. Pictures taken during the site visits and a picture atlas portraying African leafy vegetables were used as an aid during the focus group discussions.

During each focus group discussion the participants identified the four most dominant African leafy vegetables in their areas. The source (cultivated, gathered from the wild, purchased) and information on the household use were obtained for each of these plants. Aspects that were discussed included the parts of the plants that are used, preparation, processing and processing methods, beneficial traits, medicinal values, cultural beliefs and constraints for consumption, 
foods usually consumed with these vegetables, acceptability in terms of taste, and knowledge/perceptions of nutritional benefits. For plants that were cultivated (if any), additional aspects were discussed, such as cultivation practices and constraints, susceptibility to pests and diseases, water use, marketability, and the family members responsible for cultivation.

Each focus group discussion lasted approximately one hour. A facilitator chaired the discussion using a discussion guide that was compiled specifically for the study. A fieldworker recorded the session and took notes. The information was captured by transcription, translated and checked.

\section{Quantitative household survey at the rural and urban sites}

One hundred households per study area at the two rural sites, and 400 households at the urban site were randomly selected. The respondents (one per household) were interviewed in the local language by trained fieldworkers using a structured questionnaire that focused on the procurement, frequency of use and preparation methods of morogo/imifino. Socio-demographic data were collected to set the context in which the study was done.

\section{$\beta$-carotene laboratory analysis of fresh, boiled and fried amaranth}

Three sample lots of edible leaf parts of wild-growing, uncultivated amaranth were collected on the same day at the rural KZN site. The edible parts consisted of growth tips containing three to five mature leaves with stems (growth shoots) as is customarily collected for consumption by the local community. A sub-sample of these leaves were used for preparation (steamed and then fried) by a community member on the day of collection, while the remainder of the three sample lots of fresh leaves was kept in plastic containers with lids in a refrigerator at $4{ }^{\circ} \mathrm{C}$ until it was transported by air to the laboratory (in Cape Town) the following day. At the laboratory it was kept in a refrigerator overnight for analysis of fresh and boiled leaves.

\section{Fresh amaranth}

One composite sample of the raw, fresh amaranth was prepared. An equal amount of growth tips from each sample lot was combined, washed with tap water and allowed to air dry on absorbent paper for approximately two hours. The leaves were then homogenised with a hand-held stick blender and analysed in duplicate.

\section{Boiled amaranth (prepared in the laboratory)}

For each of three composite samples, an equal amount of growth tips from each sample lot was combined and washed with tap water. Approximately $2 \frac{1}{2}$ cups of water $( \pm 1.5 \mathrm{~cm}$ depth) was brought to the boil in a $24 \times 11.5 \mathrm{~cm}(5.2 \mathrm{~L}$ capacity) stainless steel pot. The washed leaves were boiled with the lid on for 15 minutes until tender. The water was drained through a sieve and after cooling the leaves were transferred to marked plastic containers with screw caps and frozen at $-20^{\circ} \mathrm{C}$ until analysis. On the day of analysis each thawed composite boiled sample was homogenised with a hand-held stick blender and analysed individually in duplicate.

\section{Fried amaranth (prepared by a community member)}

For each composite sample, an equal amount of growth tips from each sample lot was combined and washed with tap water. The washed, undrained leaves were steamed without adding water for 10 minutes, and then fried in sunflower oil for an additional 10 minutes. After cooling the leaves were transferred to marked plastic containers with screw caps and frozen at $-20^{\circ} \mathrm{C}$. It was transported in a cooler box containing ice packs by air to the laboratory (in Cape Town) the following day and kept at $-20^{\circ} \mathrm{C}$ until analysis. On the day of analysis each thawed composite fried sample was homogenised with a handheld stick blender and analysed individually in duplicate.

\section{Carotenoid extraction}

$\beta$-carotene analysis was done within one week of harvest. An aliquot of between 2.5 and $3 \mathrm{~g}$ of the homogenised sample was weighed and the carotenoids extracted with tetrahydrofuran:methanol $(1: 1, \mathrm{vol} / \mathrm{vol})$, partitioned to petroleum ether and $\beta$-carotene content determined with High Performance Liquid Chromatography (HPLC) as described in Kimura and Rodriguez-Amaya ${ }^{20}$ and Low and Van Jaarsveld. ${ }^{21}$

\section{Results}

\section{Dominant African leafy vegetables}

A wide range of different African leafy vegetables were identified during the field walks (16 different plants at the rural Limpopo site and 20 different plants at the rural KZN site). This was narrowed down during the focus group discussions to ten plants at the rural Limpopo site and six at the rural KZN site. At the rural Limpopo site, spider plant (Cleome gynandra) was the dominant African leafy vegetable (mentioned during all four group meetings), followed by amaranth (Amaranthus spp) (mentioned during three group meetings) and wild watermelon (Citrullus lanatus) leaves (mentioned during two group meetings). The remaining seven plants were each mentioned during one group meeting. At the rural KZN site, amaranth and blackjack (Bidens spinosa) were both mentioned during all four group meetings. The remaining four plants were each mentioned during two group meetings. Results from the quantitative household survey confirmed that spider plant, amaranth and wild watermelon leaves were the most frequently consumed at the rural Limpopo site, and amaranth (and to a lesser extent blackjack) the most frequently consumed at the rural KZN site.

\section{Qualitative information from observations, key informants and focus group discussions at the rural sites}

Information on the dominant African leafy vegetables (spider plant, amaranth, wild watermelon and blackjack) as obtained from the key informants and focus group discussions at the two rural sites is summarised below.

\section{Amaranth (Amaranthus spp)}

\section{- Limpopo}

At the rural Limpopo site amaranth is known as thepe. The plants grow in the wild, planting fields and household yards. Young amaranth leaves are hand picked by older women, every two to five days in summer. According to the respondents from two of the groups the leaf and the stem are eaten, while one group said that only the leaf is eaten.

Washed leaves may be dried in the shade and stored for up to one year for consumption during winter. Cooked leaves may also be dried and stored. 
During preparation, the leaves are boiled in a little water, with no water remaining after cooking. Tomatoes and salt, and sometimes onions and minestrone soup powder are added during preparation. The respondents mentioned that the leaves are never fried. Amaranth leaves are usually eaten with stiff maize meal porridge.

Amaranth leaves were seen as nutritious ("has vitamins", "prevents us from going hungry", "feel very strong") and as good for the complexion ("freshens our skins"). Some respondents said that amaranth is good for constipation ("it makes the stomach loose"). This was echoed by others who said that if the first plants of the season are eaten with charcoal it prevents constipation or stomach problems. Two of the groups felt that the leaves could be sold for a source of income. Amaranth was not seen as the most popular morogo. It was regarded as less popular than spider plant, but better tasting than spinach.

\section{- KwaZulu-Natal}

At the rural KZN site amaranth is known as imbuya. The plants grow in the wild, planting fields and household yards. Amaranth is not cultivated. The leaves are picked weekly in summer after the first rains, mostly by older women. The leaves are stored in a fridge if electricity is available. The respondents mentioned that the leaves are not dried.

During preparation, the leaves are usually washed, chopped and steamed in the water left over from washing until just tender, and then fried in oil. The leaves form their own juice during boiling - this is discarded after boiling. Less often the leaves are boiled in salted water. Oil and onions, and to a lesser degree curry powder and soup powder, are added during preparation. Amaranth is usually eaten with either stiff maize meal porridge or homemade bread.

Amaranth was seen as nutritious ("gives us vitamins which is very important"), filling ("fills us up") and an energy booster ("gives energy as a booster"). The leaves are available throughout summer and are therefore popular. Knowledge of the plant was passed down over generations. It was seen as an integral part of nature, helping with soil fertility. The respondents did not mention any cultural beliefs associated with amaranth. They did note that individuals eating it were regarded as poor and unable to afford other food. It was seen as having commercial possibilities as some said they had seen it being sold in towns. Amaranth was preferred above spinach.

\section{Spider plant (Cleome gynandra)}

At the rural Limpopo site spider plant is known as lerotho. The plants grow in the wild, on mountain slopes, in planting fields and household yards. When collected from the wild, young leaves with stems are hand picked regularly (daily up to every third day) by older women in summer after the rains (it can be harvested until autumn).

Spider plant is cultivated in the planting fields or home gardens by older women. Seeds are obtained from older plants, dried and stored in a bottle or plastic bag until being planted during summer after the rains. Production mainly depends on the rain. Manure is used as fertiliser. The plants are susceptible to various pests, such as locusts and worms. The cultivated leaves are sold within the community.

Washed leaves may be dried in either the shade or the sun, and stored in a packet for consumption in winter. The dried leaves are usually stored for three to four months, and in some cases for up to one year.
During preparation, the leaves are boiled with a little water for an hour to an hour and a half. Food items added during preparation are mostly tomatoes and salt, and sometimes onions, oil and minestrone soup powder. No or little water remains after cooking, but if water is retained it may be used for soup. Although they do not fry the fresh leaves, they do fry the dried leaves in oil, adding tomatoes and salt. The leaves are usually eaten with maize meal porridge, sorghum porridge or peanut butter. Sometimes spider plant and amaranth leaves are mixed.

The respondents valued spider plant because it occurs naturally and does not have to be bought. "Once it starts to rain everybody is happy because then the lerotho is coming." It was recognised as the "best" morogo on account of its taste ("it is the best and very nice") and was regarded as very nutritious; "having it is just like having meat". It tastes better than spinach (which has a "bad taste"). Respondents said it could be grown commercially. They learnt about its usage from their grandparents. According to one of the groups it sometimes helps with constipation. One group reported that when spider plant is eaten for the first time, you need to eat charcoal (from a fire) before you eat the leaves to prevent constipation or an upset stomach.

\section{Wild watermelon (Citrullus lanatus)}

At the rural Limpopo site wild watermelon is known as mochacha. The plants grow in the wild. The leaves, which are available in summer, are picked daily by older women. Leaves of any age are consumed. The leaves are usually boiled, and salt and tomato are added. The leaves may be dried and kept for consumption during winter.

Wild watermelon is cultivated in community gardens by older women. The respondent was not sure whether the plants are susceptible to pests and diseases. The plants need little water. No fertiliser is used. The cultivated plants are used for household consumption; they are not sold. Although wild watermelon is cultivated, one of the respondents mentioned that a lot of willpower is needed to cultivate the plants, as some people do not really see the benefit of cultivating something that grows in abundance in the wild.

\section{Blackjack (Bidens spinosa)}

At the rural KZN site blackjack is known as uqadolo. The plants grow in fertile soil in the wild and in planting fields and gardens. They are also found on river banks throughout the year. Blackjack is not cultivated. In summer the leaves are picked weekly by older women (in winter leaves are picked from plants growing next to the river). According to the participants of the focus group discussions, blackjack cannot be stored for more than one day and is therefore consumed on the day it is harvested. According to the key informant, however, leaves could be stored in a fridge until consumed.

During preparation, the fresh leaves are boiled in no or a little water for up to an hour because it is "harder" than other varieties of imifino. It is then fried in oil. Onions and salt are added during preparation. Any water remaining after boiling is discarded. According to the key informant, only parts of the stem and leaf (not the entire leaf) are used. Blackjack is usually eaten with stiff maize meal porridge and sometimes with beans (legumes). One of the groups mentioned that blackjack cannot be eaten on its own - it must be mixed with other imifino. 
Blackjack is appreciated because it is naturally available, particularly during winter when most of the other imifino is not available. It was considered nutritious. Respondents commented that children with flu drank the leaf extract, or ill children were bathed in it. It was also said to help with high blood pressure. Some of the respondents said they preferred blackjack to spinach because of its taste, while others said that spinach could be planted and was therefore better. It was not seen as having commercial value.

\section{Procurement and consumption of morogo/imifino by households based on quantitative surveys at the rural and urban sites}

In total, 592 respondents were interviewed (rural Limpopo $\mathrm{n}=100$; rural KZN $n=101$; urban KZN $n=391$ ). Their age, educational and household characteristics are presented in Table I. The rural KZN respondents were slightly older and had lower educational levels than the respondents at the other two sites. The urban KZN site was the best serviced and the rural Limpopo site the least serviced area in terms of potable water, electricity and sanitation.

Table I: Age, educational and household characteristics of the respondents included in the quantitative questionnaire survey

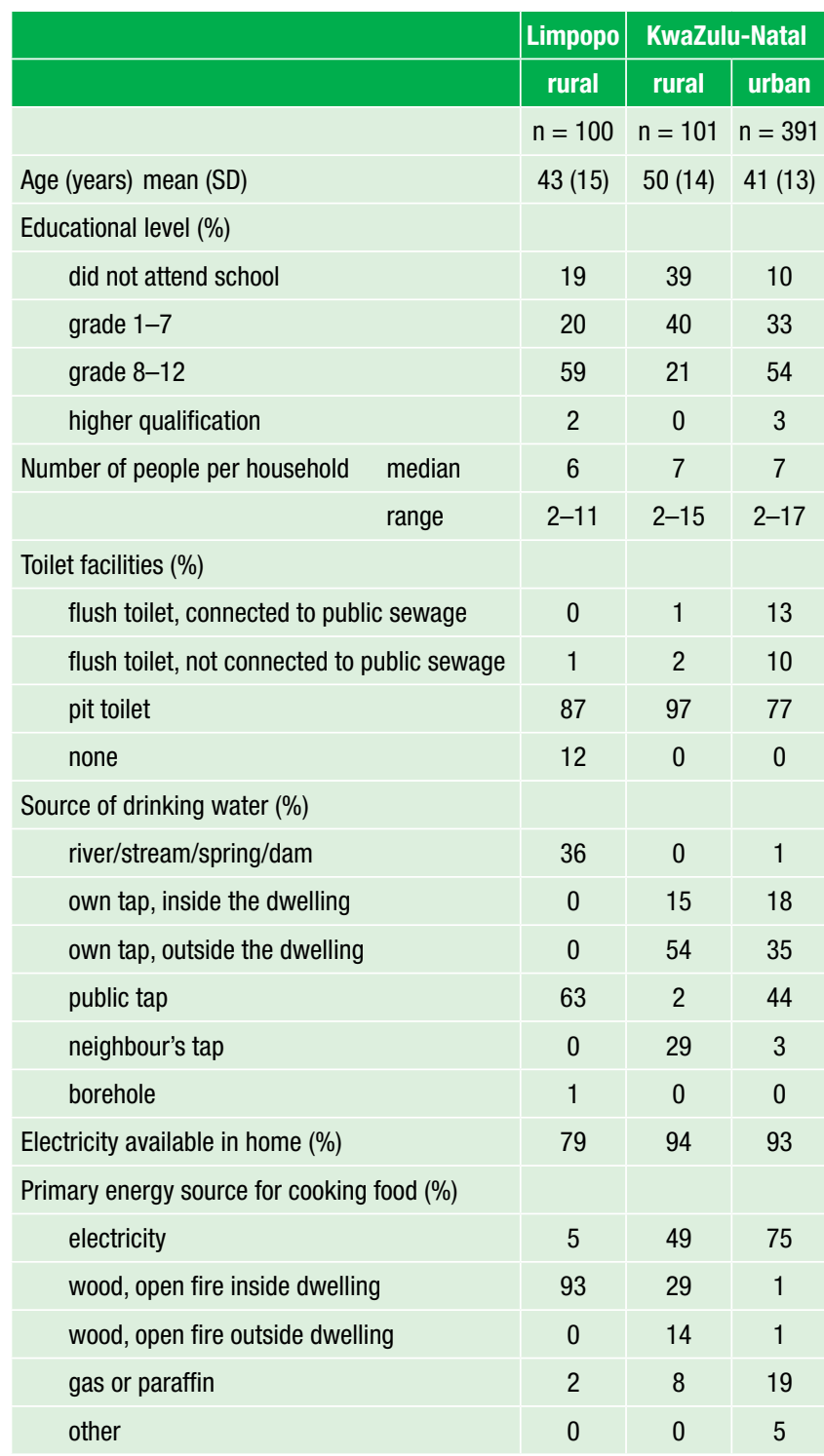

Note: Some of the column totals add up to 101 because of rounding of numbers
Table II: African leafy vegetables gathered from the wild

\begin{tabular}{|c|c|c|c|}
\hline & \multirow{2}{*}{\begin{tabular}{|c|} 
Limpopo \\
rural
\end{tabular}} & \multicolumn{2}{|c|}{ KwaZulu-Natal } \\
\hline & & rural & urban \\
\hline & $n=100$ & $n=101$ & $\mathrm{n}=391$ \\
\hline $\begin{array}{l}\text { Percentage of households collecting green leafy } \\
\text { vegetables from the wild }\end{array}$ & 100 & 66 & 39 \\
\hline $\begin{array}{l}\text { People usually collecting the leaves from the } \\
\text { wild }^{\mathrm{a}}(\%)\end{array}$ & $n=100$ & $\mathrm{n}=67$ & $n=153$ \\
\hline older women & 67 & 87 & 67 \\
\hline younger women & 86 & 42 & 46 \\
\hline younger men & 1 & - & - \\
\hline children, girls & 10 & 21 & 11 \\
\hline children, boys & - & - & 3 \\
\hline Leaves collected from the wild $(\%)$ & $\mathrm{n}=100$ & $\mathrm{n}=101$ & $n=391$ \\
\hline amaranth & 89 & 54 & 37 \\
\hline blackjack & - & 49 & 21 \\
\hline devil's thorn & 38 & - & - \\
\hline jew's mallow & 21 & - & - \\
\hline lehlanye & 50 & - & - \\
\hline spider plant & 86 & - & - \\
\hline wild watermelon & 58 & - & - \\
\hline
\end{tabular}

a Expressed as a percentage of those households who usually collect African leafy vegetables ${ }^{\mathrm{b}}$ African leafy vegetables gathered from the wild by at least $20 \%$ of the households who usually collect them

All the households at the rural Limpopo site usually collected African leafy vegetables from the wild, versus $66 \%$ at the rural KZN site and $39 \%$ at the urban KZN site; mostly women collected the leaves (see Table II). The African leafy vegetables that were usually (regardless of the season) collected by at least $20 \%$ of the households are shown Table II, while Table III reflects the main source and season of availability. Households at the rural Limpopo site collected a bigger variety of leaves than households at the two KZN sites. Amaranth and spider plant were the most popular leaves collected at the rural Limpopo site, followed by wild watermelon and lehlanye (probably a Centaurea species). Amaranth and blackjack were the most popular leaves collected at the two KZN sites. From Table III it is clear that African leafy vegetables are available mostly during summer, and are typically collected from the wild.

Table IV reflects the respondents' perceptions of imifino/morogo. Most of the respondents thought that imifino/morogo was good for them, for a variety of reasons. Thirteen percent of the respondents at the rural KZN site said that imifino is good because it contains vitamin $A$, probably reflecting the effect of a home-garden project that was previously done in the area. ${ }^{19}$ Between 20 and $28 \%$ of the respondents at the two KZN study sites thought that consumption of imifino saves money (they do not have to buy it because it is freely available). At the rural Limpopo site there clearly is a transfer of knowledge within the households, as mothers and grandmothers were the main source of information on morogo. The radio and clinic staff were important sources of information on imifino at the KZN study sites.

The frequency of household consumption of imifino/morogo is summarised in Table V. Households at the rural Limpopo site had the highest frequency of consumption during the month prior to 
Table III: The main source of and season for collecting leaves for African leafy vegetables collected by at least $20 \%$ of the households

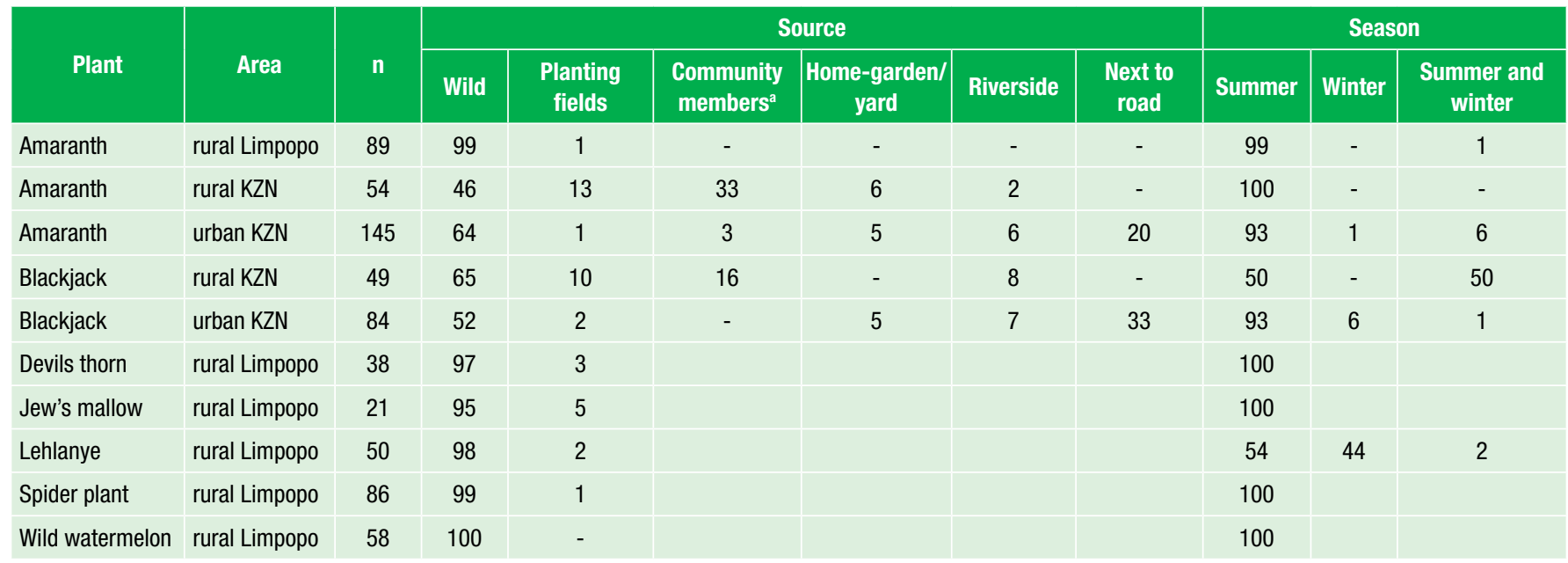

All values are given as a percentage of those households that usually collect the specific leaves

a From friends, family or neighbour

Table IV: Respondents' perception of imifino/morogo

\begin{tabular}{|c|c|c|c|}
\hline & \multirow{2}{*}{\begin{tabular}{|c|} 
Limpopo \\
rural \\
\end{tabular}} & \multicolumn{2}{|c|}{ KwaZulu-Natal } \\
\hline & & rural & urban \\
\hline & $n=100$ & $\mathrm{n}=101$ & $\mathrm{n}=308^{\circ}$ \\
\hline & $\%$ & $\%$ & $\%$ \\
\hline \multicolumn{4}{|l|}{ Imifino/morogo is good for you } \\
\hline yes & 99 & 92 & 77 \\
\hline no & 1 & - & 6 \\
\hline unsure & - & 8 & 17 \\
\hline \multicolumn{4}{|c|}{ Apart from being healthy, reasons why imifino/morogo is good for people ${ }^{b}$} \\
\hline gives energy & 13 & - & 4 \\
\hline gives strength & 28 & 11 & 18 \\
\hline strong bones & - & - & 6 \\
\hline prevent illness & 20 & - & - \\
\hline contains vitamins & 9 & 8 & - \\
\hline contains vitamin $A$ & - & 13 & - \\
\hline saves money & - & 28 & 20 \\
\hline live longer & 9 & - & - \\
\hline \multicolumn{4}{|c|}{ Information source for the use of imifino/morogo } \\
\hline radio & 3 & 61 & 62 \\
\hline clinic & 22 & 70 & 90 \\
\hline community health workers & - & 2 & 13 \\
\hline mother/grandmother & 86 & 28 & 18 \\
\hline family other than mother/grandmother & 2 & 3 & 12 \\
\hline newspapers/magazines & 2 & - & 8 \\
\hline friends & - & 3 & 3 \\
\hline project nutrition monitors ${ }^{c}$ & - & 56 & - \\
\hline nowhere & - & - & 7 \\
\hline
\end{tabular}

${ }^{a}$ Missing data because of a printing error in the questionnaire, which was corrected after some of the respondents were already interviewed

${ }^{b}$ Only answers for those reasons given by more than $5 \%$ of the respondents are reflected

${ }^{c} \mathrm{~A}$ home-garden project focusing on $\beta$-carotene-rich vegetables was done in the area from 1998 to $2002^{19}$; nutrition monitors were responsible for the daily activities

the survey, while households at the urban KZN site had the lowest frequency of consumption. For those respondents who consumed imifino/morogo the previous month, $94 \%$ of the respondents at the rural Limpopo site obtained the leaves from the wild, versus $53 \%$ at the rural KZN site and $38 \%$ at the urban KZN site.

All of the households at the rural Limpopo site, $97 \%$ of the households at the rural KZN site and $78 \%$ of the households at the urban KZN site had consumed imifino/morogo the week prior to the survey. At the urban KZN site the two main reasons for not having consumed imifino the previous week were personal preference $(43 \%)$ and the unavailability of leaves (32\%).

Nearly all (99\%) of the households at the rural Limpopo site had consumed imifino/morogo the day before the survey, versus $30 \%$ at the rural KZN site and $19 \%$ at the urban KZN site. Most of these KZN households ate imifino/morogo once during the day, whereas $58 \%$ of the rural Limpopo households ate it at least twice a day. Imifino/ morogo was consumed during all three main meals and during midmorning at the rural Limpopo site, whereas at the KZN sites it was consumed during either lunch or supper.

Using a five-point hedonic scale with smiley faces showed that the imifino/morogo consumed the day before was well liked by most of the respondents. However, it was the perception of the respondents at the Limpopo site and the urban KZN site that the imifino/morogo was not that well liked by their children.

Of those households who reportedly consumed imifino/morogo the day before the study, some consumed beetroot and turnip leaves, particularly at the KZN sites. All cases where these leaves were eaten without other African leafy vegetables were excluded from further data analysis.

For the 100 respondents at the rural Limpopo site, consumption of African leafy vegetables the previous day was reported for 164 meals. The leaves mostly consumed were spider plant $(51 \%$ of the time), wild watermelon ( $27 \%$ of the time) and amaranth $(24 \%$ of the time), either on their own or in combination with other leaves. For $98 \%$ of the cases the African leafy vegetables were collected from the wild. Ingredients added during preparation were salt (98\%), tomato $(69 \%)$, oil $(1 \%)$ and peanut butter $(1 \%)$. Nearly all of the respondents (98\%) added water during preparation, with either only the bottom of the pot $(31 \%)$, half of the leaves $(57 \%)$ or all of the leaves $(10 \%)$ covered with water. Only one respondent changed the 
Table V: The frequency of household consumption and source of imifino/morogo

\begin{tabular}{|c|c|c|c|} 
& Limpopo & \multicolumn{2}{|c|}{ KwaZulu-Natal } \\
\hline & rural & rural & urban \\
\hline & $\mathrm{n}=100$ & $\mathrm{n}=101$ & $\mathrm{n}=391$
\end{tabular}

Frequency of imifino/morogo consumption the past month (\%)

$$
\begin{aligned}
& \text { every day ( } 7 \text { days a week) } \\
& \text { most days ( } 4-6 \text { days a week) } \\
& \text { once a week (1-3 days a week) } \\
& \text { seldom (once or twice a month) } \\
& \text { never }
\end{aligned}
$$

Source of imifino/morogo (\%)

bought / informal market

household yard / home garden

community garden

wild

next to river

from planting fields

Percentage of respondents who ate imifino/ morogo during the previous week

Number of days imifino/morogo was consumed the previous week mean (SD)

Percentage of respondents who ate imifino/ morogo the day before the survey

Number of times imifino/morogo was consumed the day before $(\%)$

once

three times

Meal during which imifino/morogo was consumed (\%)

breakfast

mid-morning

lunch

mid-afternoon

supper

How much did you like the imifino/morogo that you ate yesterday? (\%)

bad

indifferent

nice

very nice

How much do you think your children liked the imifino/morogo that was eaten yesterday? (\%)

very bad

bad

indifferent

nice

very nice

Expressed as a percentage of those respondents who consumed green leafy vegetables during the previous month; households could obtain the leaves from more than one source water during cooking. Most (95\%) of the respondents said that there was no water left after cooking.

For the 101 respondents at the rural KZN site, consumption of African leafy vegetables the previous day was reported for 22 meals. The leaves mostly consumed were amaranth $(82 \%$ of the time), either on its own or in combination with other leaves (mostly blackjack). The leaves consumed the previous day were collected from the wild $(33 \%)$, household yards $(38 \%)$, river banks $(10 \%)$, planting fields $(10 \%)$, or obtained from other community members $(10 \%)$. Ingredients added during preparation were onion (100\%), salt $(100 \%)$, oil $(96 \%)$, stock cubes $(41 \%)$ and tomato $(18 \%)$. None of the respondents added water during preparation.

For the 391 respondents at the urban KZN site, consumption of African leafy vegetables the previous day was reported for 54 meals. The leaves mostly consumed were amaranth ( $87 \%$ of the time), either on its own or in combination with other leaves (mostly blackjack). The leaves consumed the previous day were collected from the wild $(35 \%)$, household yards $(28 \%)$ or next to road $(20 \%)$, or were obtained from either people who were selling it $(9 \%)$ or other community members $(6 \%)$. Ingredients added during preparation were onion $(100 \%)$, oil $(98 \%)$, salt $(91 \%)$, tomato $(46 \%)$, stock cubes $(20 \%)$ and peanut butter (2\%). One respondent added bicarbonate of soda to the leaves. (Bicarbonate of soda is often added to mucilaginous species to reduce the slimy texture - personal communication Sophie Sitole.) The majority (87\%) of the respondents did not add water during preparation. Of the seven respondents who used water during cooking, five changed the water during cooking.

\section{$\beta$-carotene content of fried, boiled and fresh amaranth}

Amaranth emerged as the African leafy vegetable that is popular in both provinces. The $\beta$-carotene content of fried, boiled and fresh amaranth (per $100 \mathrm{~g}$ edible portion) is presented in Table VI. The mean vitamin A value ( $\mu \mathrm{g}$ retinol activity equivalents; RAE) of fresh, boiled and fried amaranth was $421 \mu \mathrm{g}$ RAE/100 g, $429 \mu \mathrm{g}$ RAE/100 $\mathrm{g}$ and $627 \mu \mathrm{g} R \mathrm{RE} / 100 \mathrm{~g}$ respectively.

Table VI: The $\beta$-carotene content of fresh, boiled and fried amaranth

\begin{tabular}{|l|c|c|c|}
\hline & Total $\beta$-carotene & Trans- $\beta$-carotene & Vitamin A value \\
\hline & $\mu g / 100 \mathrm{~g}$ & $\mu g / 100 \mathrm{~g}$ & $\mu g$ RAE/100 g \\
\hline Fresh leaves & $6156(120)$ & $5047(94)$ & $421(8)$ \\
\hline Boiled leaves & $6472(102)$ & $5151(85)$ & $429(7)$ \\
\hline Fried leaves & $9230(383)$ & $7526(302)$ & $627(25)$ \\
\hline
\end{tabular}

$\mathrm{SD}=$ standard deviation

Vitamin A value calculated from all-trans- $\beta$-carotene; $12 \mu \mathrm{g} \beta$-carotene $=1 \mu \mathrm{g}$ retinol activity equivalents $(\mathrm{RAE})=1 \mu \mathrm{g} \mathrm{retinol}^{22}$

\section{Discussion}

This study showed that African leafy vegetables were commonly consumed in the study areas, mostly because they are a free source of nutritious food that can be easily accessed and regularly harvested during the growing season. The more frequent consumption and the larger variety of African leafy vegetables at the rural Limpopo site as compared to the rural KZN site were expected. The National Food Consumption Survey of 1999 showed that green leafy vegetables were the fourth most frequently consumed food item for one- to 
nine-year-old children in the Limpopo province (previously known as the Northern Province), while in KZN province it was the twentieth most frequently consumed food item. ${ }^{23}$ The higher consumption and the consumption of a larger variety in the Limpopo province may reflect the level of poverty forcing communities to revert to wild vegetables for nutrition.

Flyman and Afolayan ${ }^{24}$ reported that in all four districts which they studied in Botswana (geographically and climatologically closer to the rural Limpopo site of our study), Amaranthus was the preferred African leafy vegetable, followed by Cleome (spider plant). In the mid 1980s the most frequently consumed African leafy vegetable in Swaziland (geographically and climatologically closer to KZN) was Bidens spp (blackjack), followed by Corchorus spp and Amaranthus spp. ${ }^{25}$ In general, amaranth has also been identified as an important leafy vegetable in the lowlands of Africa and Asia. ${ }^{26}$ In line with the aforementioned and other South African studies, ${ }^{27,28}$ the current study showed that although amaranth is not always the most popular imifino/morogo, it is always amongst the most important consumed species. According to Vorster, ${ }^{28}$ some ethnic groups prefer the "stronger" taste of other species, but they use amaranth to supply the bulk.

Analysis for $\beta$-carotene content of both fried and boiled amaranth showed that these leaves provide considerable quantities of vitamin A ( $\mu \mathrm{g}$ RAE) per $100 \mathrm{~g}$ edible portion. The $\beta$-carotene content of fried amaranth was higher than that of boiled amaranth. This is understandable considering the higher temperature generated during frying, resulting in greater moisture loss from fried leaves compared to boiled leaves. ${ }^{29}$ Nevertheless, both fried and boiled amaranth provided considerable quantities of vitamin A ( $\mu$ g RAE) per $100 \mathrm{~g}$, suggesting that amaranth can potentially contribute significantly to vitamin A requirements of nutritionally vulnerable communities. For example, a portion of $100 \mathrm{~g}$ boiled or fried amaranth will provide more than half of the recommended dietary allowance for vitamin A for adult females. ${ }^{22}$ Consumption of cooked green leafy vegetables has been shown to improve vitamin A status. ${ }^{13-15}$

Addition of oil during the preparation of green leafy vegetables increases the bioavailability of $\beta$-carotene ${ }^{30}$; between $3^{31}$ and $5 \mathrm{~g}^{32}$ of fat is needed in the meal to enhance $\beta$-carotene absorption. A recent study showed that a minimal amount of fat (as low as 2.4 $\mathrm{g}$ ) is needed for optimal bioavailability and effectiveness of plant carotenoids. ${ }^{33}$ At both the KZN study sites oil was added during preparation, which can be expected to enhance the nutritional benefits from the leaves in terms of vitamin A. However, at the rural Limpopo site no oil was added to the dish, and the leaves were eaten mostly with a starchy staple, which would limit the bioavailability of $\beta$-carotene. For maximum benefit the addition of a little fat should thus be encouraged. However, considering the high prevalence of adult obesity and escalating overweight observed in children in the country, ${ }^{34}$ this should be done in moderation.

African leafy vegetables can potentially contribute towards the dietary requirements of micronutrients other than $\beta$-carotene, such as calcium, magnesium, iron, potassium, zinc and vitamin $\mathrm{C}$, although the bioavailability of some of these micronutrients is affected by the oxalates, phytates and nitrates present in the leaves. ${ }^{35}$ Wild-growing green leafy vegetables are generally richer sources of various micronutrients than exotic or commercially produced leafy vegetables..$^{35-37}$
This study confirms the general belief that information on African leafy vegetables is passed down over generations. There are, however, indications from the KZN sites that clinics and radio are also an important source of information on imifino, pointing to these as potentially worthwhile communication channels for nutritional promotion of these leaves.

The respondents reported that the leaves were available mostly during summer, which is in line with the findings of other studies. ${ }^{27,28}$ The importance of location on the availability of green leafy vegetables is illustrated by the period of availability of blackjack for the two KZN sites (which are approximately $20 \mathrm{~km}$ apart). At the rural KZN site, where a river is flowing through the village, blackjack is available during winter, growing on the river banks, while in the urban site, where there is no river, it is available only in summer. Blackjack, a foreign weed most probably introduced to South Africa with horse fodder during the early 1900s, is one example of an introduced/ exotic species that became part of the culinary heritage. ${ }^{38}$

This study was done during the rainy summer months, as most of the wild-growing species that are consumed grow in summer. ${ }^{39} \mathrm{~A}$ study previously done at the rural KZN site showed that consumption of imifino (consumed during the first and last quarter of the year; summer) and spinach, mostly Swiss chard (consumed during the third quarter of the year; winter) complemented each other..$^{40}$ The authors therefore concluded that imifino should be promoted together with consumption of locally produced or commercially available spinach (a cool weather crop) to ensure a year-round consumption of darkgreen leafy vegetables to ensure a sustainable delivery of nutrients to these communities.

Drying the leaves for consumption during winter was observed at the rural Limpopo site, a practice that has been reported previously. ${ }^{28,41}$ The leaves are dried either in the sun or in the shade. Tanzanian studies have suggested that the traditional processing practices of sun-drying reduce the concentration of carotenoids. ${ }^{42,43}$ It is therefore important that drying and storage conditions are optimised in order to minimise nutrient loss.

While rural households obtained the leaves mostly from the wild, urban households relied to a great extent on the informal market sector for access. The trading of imifino at some urban informal markets in KZN has been observed (personal observation), and is confirmed by market surveys done in other parts of South Africa, e.g. Soshanguve and Durban. ${ }^{44}$ It is not known whether the vendors source the leaves from the wild or from home gardens, and from how far a distance they source it. The trading of African leafy vegetables in informal urban markets does show, however, that these leaves may have commercial value. Although cultivation of African leafy vegetables is very limited in Southern Africa, the explorative phase of this study suggested that some of the leaves could be cultivated. Pasquini and colleagues ${ }^{44}$ reported that some farmers do grow African leafy vegetables for trading (as extra income).

African leafy vegetables are often regarded as a poor person's food. ${ }^{28}$ In the current study, this was only found to be the case in the rural KZN site. Approximately a quarter of the respondents of the quantitative survey thought that consumption of imifino is good because "it saves money". They generally regarded African leafy vegetables as a poor person's food, and people who ate imifino were 
generally judged as "being poor" and "having no food". The aspect of affordability should therefore be avoided or used carefully during promotion, as to avoid the perception that African leafy vegetables are food for the poor. The emphasis should rather be on the potential nutritional and hence health benefits the consumption of these vegetables could offer.

The promotion and study of African leafy vegetables should be approached within a framework of holism and interrelatedness. Such a model, which includes nutrition and health status, sociocultural traditions, income generation, and biodiversity conservation for developing-country food systems, has been published by Johns and Sthapit. ${ }^{45}$

Concerns have been raised regarding the lack of documentation of traditional and indigenous food cultures ${ }^{46}$ This study contributes to the much needed documentation of regional food culture in order to explore the potential benefits for nutrition and food security. Differences between provinces, as well as rural/urban differences within a province, in terms of type and source of African leafy vegetables, preparation methods, consumption patterns and preference were observed. The differences between the two rural sites could probably be ascribed to geographical differences, ethnic/ cultural difference, knowledge transfer differences and/or preference differences. Data on the use of African leafy vegetables should therefore be reported within the context of the area from where the information was collected. It is evident that information collected by small studies within a specific area cannot be generalised for the overall South-African population.

\section{Acknowledgements}

This project was initiated, funded and managed by the Water Research Commission of South Africa under project K5/1579//4.

The authors acknowledge Peter Jacobusen (Dynamic Research) and his fieldworkers for doing the key interviews, focus group discussions and household questionnaires in the rural Limpopo site; Bongi Duma and Angeline Ntshangase for recruitment of key informants and participants for focus group discussions, assistance with the interviews and group discussions and completion of questionnaires in the rural KZN site; Eunice Maphumulo and the community members who assisted for completion of questionnaires in the two KZN study sites; Bongi Duma for preparing the fried amaranth; Daniel Barrett for data capturing; Lee-Ann Human for data capturing and data cleaning; Eldrich Harmse for laboratory assistance; and the research respondents who participated in the study.

\section{References}

Ezzati M, Lopez AD, Rodgers A, Vander Hoorn S, Murray CJL. Selected major risk factors and global and regional burden of disease. Lancet 2002;360:1347-60.

2. Diet, nutrition and the prevention of chronic diseases. Joint WHO/FAO expert consultation. WHO technical report series no. 916. Geneva: World Health Organization; 2003

3. Rose D, Bourne L, Bradshaw D. Food and nutrient availability in South African households. Development of a nationally representative database. Parow: Medical Research Council; 2002.

4. Love P, Maunder E, Green M, Ross F, Smale-Lovely J, Charlton K. South African food-based dietary guidelines. Testing of the preliminary guidelines among women in KwaZulu-Natal and the Western Cape. $S$ Afr J Clin Nutr 2001:14:9-19.

5. Smith IF, Eyzaguirre P. African leafy vegetables: their role in the World Health Organization's global fruit and vegetable initiative. Afr J Food Agric Nutr Develop 2007. Available from http://www.ajfand.net.index $\mathrm{html}$ (Accessed 06/06/2007).

6. Global prevalence of vitamin A deficiency in populations at risk 1995-2005. WH0 global database on vitamin A deficiency. Geneva: World Health Organization; 2009.

7. Black RE, Allen LH, Bhutta ZA, et al. Maternal and child undernutrition: global and regional exposures and health consequences. Lancet 2008;371:243-60.

8. Labadarios D (ed). National Food Consumption Survey - Fortification Baseline (NFCS-FB): South Africa,
2005. Pretoria: Department of Health; 2007.

9. Kiess L Moench-Pfanner R, Bloem M. Food-based strategies: can they play a role in international development? Food Nutr Bull 2001:22(4):436-42.

10. Ruel MT. Addressing the underlying determinants of undernutrition: examples of successful integration of nutrition in poverty-reduction and agriculture strategies. SCN News No 36. Geneva: Standing Committee on Nutrition; 2008:21-9.

11. De Pee S, West CE, Muhilal, Karyadi D, Hautvast JGA. Lack of improvement in vitamin A status with increased consumption of dark-green leafy vegetables. Lancet 1995;46(8967):75-81.

12. Khan NC, West CE, De Pee S, et al. The contribution of plant foods to the vitamin A supply of lactating women in Vietnam: a randomized controlled trial. Am J Clin Nutr 2007;85:1112-20.

13. Takyi EEK. Children's consumption of dark green, leafy vegetables with added fat enhances serum retinol. J Nutr 1999;129:1549-54.

14. Haskell MJ, Jamil KM, Hassan F, et al. Daily consumption of Indian spinach (Basella alba) or sweet potatoes has a positive effect on total-body vitamin A stores in Bangladeshi men. Am J Clin Nutr 2004;80:705-14.

15. Haskell MJ, Pandey P, Graham JM, Peerson JM, Shrestha RK, Brown KH. Recovery from impaired dark adaptation in nightblind pregnant Nepali women who receive small daily doses of vitamin $A$ as amaranth leaves, carrots, goat liver, vitamin A-fortified rice, or retinyl palmitate. Am J Clin Nutr 2005;81:461-71.

16. Flyman MV, Afolayan AJ. The suitability of wild vegetables for alleviating human dietary deficiencies. S Afr J Botany 2006;72:492-7.

17. Odhav B, Beekrum S, Akula U, Baijnath H. Preliminary assessment of nutritional value of traditional leafy vegetables in KwaZulu-Natal, South Africa. J Food Comp Anal 2007;20:430-5.

18. Toledo A, Burlingame A. Biodiversity and nutrition: a common path toward global food security and sustainable development. J Food Comp Anal 2006;19:477-83.

19. Faber M, Phungula MAS, Venter SL, Dhansay MA, Benadé AJS. Home gardens focusing on the production of yellow and dark-green leafy vegetables increase the serum retinol concentrations of 2-5-y- old children in South Africa. Am J Clin Nutr 2002;76:1048-54.

20. Kimura M, Rodriguez-Amaya DB. A scheme for obtaining standards and HPLC quantification of leafy vegetable carotenoids. Food Chem 2002;78:389-98.

21. Low J, Van Jaarsveld PJ. The potential contribution of bread buns fortified with beta-carotene-rich sweet potato in Central Mozambique. Food Nutr Bull 2008:29:98-107.

22. Trumbo P, Yates AA, Schlicker S, Poos M. Dietary Reference Intakes: vitamin A, vitamin K, arsenic, boron chromium, copper, iodine, iron, manganese, molybdenum, nickel, silicon, vanadium, and zinc. J Am Diet Assoc 2001;101:294-301.

23. Labadarios D, Steyn N, Maunder E, et al. The National Food Consumption Survey (NFCS): Children aged 1-9 years, South Africa, 1999. Pretoria: Department of Health: Directorate of Nutrition; 2000.

24. Flyman MV, Afolayan AJ. A survey of plants used as wild vegetables in four districts of Botswana. Ecol Food Nutr 2006;45:405-415

25. Ogle BM, Grivetti LE. Legacy of the chameleon: edible wild plants in the Kingdom of Swaziland, Southern Africa. A cultural, ecological, nutritional study. Part II - Demographics, species availability and dietary use, analysis by ecological zone. Ecol Food Nutr 1985:17:1-30.

26. Palada MC, Chang LC. Suggested cultural practices for vegetable amaranth. Asian Vegetable Research and Development Center; 2003. Available from http://www.avrdc.org/LC/indigenous/amaranth.pd (Accessed 01/07/2009)

27. Steyn NP, Burger S, Monyeki KD, Alberts M, Nthangeni G. Seasonal variation in dietary intake of the adult population of Dikgale. S Afr J Clin Nutr 2001:14:40-145.

28. Vorster HJ. The role and production of traditional leafy vegetables in three rural communities in South Africa [MSc thesis]. Pretoria: University of Pretoria; 2007. Available from http://upetd.up.ac za/thesis/ available/etd-02122009-115129/ (Accessed 08/07/2009).

29. Greenfield H, Southgate DAT. Food composition data. Rome: Food and Agriculture Organization of the United Nations; 2003.

30. Hedrén E, Mulokozi G, Svanberg U In vitro accessibility of carotenes from green leafy vegetables cooked with sunflower oil or red palm oil. Int J Food Sci Nutr 2002:53:445-53.

31. Jalal F, Nesheim MC, Agus Z, Sanjur D, Habicht JP. Serum retinol concentrations in children are affected by food sources of $\beta$-carotene, fat intake, and anthelmintic drug treatment. Am J Clin Nutr 1998;68:623-9.

32. Jayarajan $P$, Reddy V, Mohanram M. Effect of dietary fat on absorption of $\beta$-carotene from green leafy vegetables in children. Ind J Med Res 1980;71:53-66.

33. Ribaya-Mercado JD, Maramag CC, Tengco LW, Dolnikowski GG, Blumberg JB, Solon FS. Carotenerich plant food ingested with minimal dietary fat enhance the total-body vitamin A pool size in Filipino schoolchildren as assessed by stable-isotope-dilution methodology. Am J Clin Nutr 2007;85:1041-9.

34. South African Demographic and Health Survey, 2003. Pretoria: Department of Health; 2007:276-7.

35. Steyn NP, Olivier J, Winter P, Burger S, Nesamvuni C. A survey of wild, green, leafy vegetables and their potential in combating micronutrient deficiencies in rural populations. S Afr J Sci 2001:97:276-8.

36. Kobori CN, Rodriguez-Amaya DB. Uncultivated Brazilian leaves are richer sources of carotenoids than commercially produced leafy vegetables. Food Nutr Bull 2008;29:320-8.

37. Su Q, Rowley KG, Itsiopoulus C, O'Dea K. Identification and quantification of major carotenoids in selected components of the Mediterranean diet: green leafy vegetables, figs and olive oil. Eur J Clin Nutr 2002;56:1149-54.

38. Macdonald IAW, Reaser JK, Bright C, et al. Invasive alien species in southern Africa: national reports and directory of resources. Cape Town: Global Invasive Species Programme; 2003.

39. Jansen van Rensburg WS, Van Averbeke W, Slabbert R, et al. African leafy vegetables in South Africa. Water SA 2007;33(3) (special issue):317-26.

40. Faber M, Van Jaarsveld PJ, Laubscher R. The contribution of dark-green leafy vegetables to total micronutrient intake of two- to five-year-old children in a rural setting. Water SA 2007:33(3) (specia issue):407-12.

41. Nesamvuni C, Steyn NP, Potgieter MJ. Nutritional value of wild, leafy plants consumed by the Vhavenda S Afr J Sci 2001;97:51-4.

42. Mosha TC, Pace RD, Adeyeye S, Laswai HS, Mtebe K. Effect of traditional processing on the tota carotenoid, $\beta$-carotene, $\beta$-carotene and vitamin $A$ activity of selected Tanzanian vegetables. Plant Food Hum Nutr 1997:50:189-201.

43. Mulokozi G, Svanberg U. Effect of traditional sun-drying and solar cabinet drying on carotene content and vitamin A activity of green leafy vegetables. Plant Food Hum Nutr 2003;58:1-15

44. Pasquini MW, Assogba-Komlan F, Vorster HJ, Shackleton CM, Abukuysa-Onyango MO. The production of African indigenous vegetables in urban and peri-urban agriculture: a comparative analysis of case studies from Benin, Kenya and South Africa. In: Shackleton CM, Pasquini MW, Drescher AW, eds. African indigenous vegetables in urban and peri-urban agriculture. London: Earthscan; 2009:177-224.

45. Johns T, Sthapit BR. Biocultural diversity in the sustainability of developing-country food systems. Food Nutr Bull 2004;25(2):143-55

46. Wahlquist M, Lee M-S. Regional food culture and development. Asia Pac J Clin Nutr 2007;16:2-7. 